Voix et Images

voixetimages

\title{
Théories du chaos et de l'anarchie
}

\section{François Paré}

Volume 28, numéro 1 (82), automne 2002

Noël Audet

URI : https://id.erudit.org/iderudit/000840ar

DOI : https://doi.org/10.7202/000840ar

Aller au sommaire du numéro

\section{Éditeur(s)}

Université du Québec à Montréal

\section{ISSN}

0318-9201 (imprimé)

1705-933X (numérique)

Découvrir la revue

\section{Citer cet article}

Paré, F. (2002). Théories du chaos et de l'anarchie. Voix et Images, 28(1),

151-166. https://doi.org/10.7202/000840ar

Tous droits de reproduction, de rédaction et d'adaptation réservés 2002 C Université du Québec à Montréal
Ce document est protégé par la loi sur le droit d'auteur. L’utilisation des services d'Érudit (y compris la reproduction) est assujettie à sa politique d'utilisation que vous pouvez consulter en ligne.

https://apropos.erudit.org/fr/usagers/politique-dutilisation/ 


\title{
Essai/Études
}

\section{Théories du chaos et de l'anarchie}

\author{
François Paré, Université de Guelph
}

Je ne sais pas si c'est la chaleur étouffante de l'été, ou encore la lecture fascinée et déprimante à la fois du roman-essai de Michel Houellebecq, Les particules élémentaires ${ }^{1}$, que je viens de terminer, ou peutêtre simplement la logorrhée publicitaire acheminée quotidiennement par mon courriel, mais un sentiment d'impuissance ne cesse de m'assaillir devant les grands courants d'insignifiance qui articulent le monde à l'heure actuelle et qui me sont parfois si étrangers. À force de peser le bouton «DELETE», on finit par croire en une pensée magique qui effacerait instantanément toute cette souillure. Mais tel n'est pas le cas. Dans L'homme symbiotique. Regards sur le troisième millénaire, Joël de Rosnay décrit l'avènement de nouvelles complexités, issues de la multiplication des processus informatiques et des théories fractales de la communication. Le discours, épousant la forme polygonale du diamant, ne peut plus être linéaire s'il veut rendre compte de la réalité actuelle: «Les processus, réseaux, systèmes s'enchevêtrent dans un maillage inextricable. Il nous faut donc de nouveaux outils, de nouvelles méthodes de pensée pour aborder une évolution dont nous sommes les acteurs principaux ${ }^{2}$.» L'univers serait en soi une «cons- cience » qui s'auto-organise, répondant aux lois scientifiques du chaos.

Bien qu'il consacre un chapitre à la culture, qu'il voit comme le point de rencontre d'une multitude d'interventions individuelles sur le temps et sur l'espace, l'auteur de L'homme symbiotique n'attribue pas à l'art ou à la littérature un rôle déterminant dans l'appréhension de cette complexité. $\mathrm{Au}$ contraire, les pratiques artistiques se présentent selon lui comme des refuges plutôt romantiques, en lutte contre les inévitables processus de dégradation de l'histoire. Les trois ouvrages qui font l'objet de la présente chronique (ma toute première en ces pages!) sont, eux aussi, à la recherche de valeurs sûres sur lesquelles fonder une morale de la complexité. Ils font appel à une certaine nostalgie de la plénitude du sens qui, au-delà du déclin présumé des valeurs sociales, permettrait de retrouver un discours plus souvent enraciné dans le réel et des identités plus clairement définies. Quelque chose comme un discours symbiotique!

$$
\text { ** }
$$

Dans Le chaos créateur, Chantal Deschamps, reprenant textuellement sa thèse sur l'étude phénoménologique de la création artistique, souhaite 
en arriver à une expérience plus positive et plus palpable de l'acte créateur $^{3}$. Désireuse de dissocier la créativité des «états pathologiques» auxquels elle est souvent liée depuis le romantisme, Deschamps sollicite l'apport de la phénoménologie husserlienne, qui lui semble mieux rendre compte de l'œuvre d'art comme résultat d'une série d'«actes intentionnels ». Elle rejette, par conséquent, toute interprétation du travail artistique qui ne serait fondée que dans le raisonnement théorique. Au contraire, la pensée de Husserl nous invite à recourir au vécu et à l'observable pour mieux saisir la complexité des processus mentaux.

Cependant, Deschamps ne soulève pas la question même de ce vécu en tant que discours rapporté, inobservable justement en dehors du langage. Dans Le chaos créateur, le vocabulaire utilisé nous entraîne plutôt dans une certaine logique du dévoilement mystique, dont l'objet serait paradoxalement de traduire la vie dans ses manifestations sensibles. Il en résulte une certaine angoisse de la dissociation et de l'arbitraire, que la thèse de Deschamps cherche à circonscrire. Qu'est-ce, en effet, que le «chaos créateur»? «Dans les faits, l'expérience du chaos m'a fait connaître des moments intenses de doute, de remise en question ainsi que de grandes solitudes, comme peut le susciter l'image du voyage initiatique aux tréfonds de l'être.» (p. 35) Cette définition permet d'imaginer une démarche intellectuelle centrée sur le refus des états troubles de la conscience et sur la quête d'une morale de l'expérience positive.

Pour les fins de sa thèse, Deschamps a interviewé des artistes visuels (dont nous ne connaissons que les prénoms), à qui elle a demandé de raconter leur propre «expérience du chaos créateur». L'argumentation théorique de l'ouvrage est donc entrecoupée de témoignages qui confirment, selon Deschamps, la validité de l'approche phénoménologique. De façon ponctuelle, les artistes interviewés évoquent la transformation personnelle, quelque peu magique, qui les a amenés à adopter un point de vue plus positif sur leurs pratiques artistiques. C'est qu'«étant vivement esseulés par l'épreuve dévastatrice du chaos, ils désirent, chacun à sa manière, rétablir le contact avec eux-mêmes et entrer en communication avec le monde extérieur. C'est ainsi que le signe d'une douce complicité s'installe dans leurs relations les disposant à s'ouvrir aux autres et à s'épancher auprès d'eux» (p. 47). Au terme de ce parcours et à la lecture des témoignages finals des artistes, nous sommes invités à accepter la part de souffrance et d'imprévisible dans tout geste de création et à laisser affleurer une expression créatrice pleinement assumée. Le chaos créateur se termine sur la lecture de nombreux passages de Mircea Eliade et de textes du bouddhisme zen.

Ce qui frappe dans cet ouvrage, ce n'est pas tant le détournement de la pensée husserlienne vers quelque avatar du Nouvel Âge, ce que cet ouvrage accomplit sans aucun doute, mais plutôt le besoin viscéral de contrer l'angoisse et la négativité qui sont à l'œuvre dans le geste créateur et d'arriver ainsi à un monde «meilleur » où fleuriraient de nouvelles utopies de la communication fraternelle. Ce faisant, Deschamps oblitère 
les ruptures transformatrices et la souffrance même dont la démarche artistique me semble avant tout porteuse.

$$
* *
$$

À son tour, Marc Vaillancourt se voit comme un «physicien de laboratoire moral ${ }^{4} »$. Dans Les feuilles de la sibylle, il rêve d'une Poésie moderne (Poésie avec un grand «P»!) qui se ressourcerait aux vers de Racine et aux textes de l'antiquité classique. Il s'en prend du même souffle aux essayistes contemporains qui, à son avis, ont détourné les pratiques littéraires de leur véritable sens. Il s'attend d'ailleurs à ce que ces mêmes critiques rejettent sa «défense de la littérature», bien que de toute façon, nous assure-t-il, il n'ait jamais cherché à plaire à ce lectorat de «coupegorge ombreux » et de «jurys de subventions». Même si «les trous de cul en mènent large, dans nos pays d'enculés »(p. 53), il espère être lu par ce qu'il appelle «les amants de l'immobile», ceux-là qui sont encore branchés sur les «grandes œuvres » léguées par l'histoire.

Je crains bien, hélas, de faire partie de ces critiques universitaires, tant honnis par Marc Vaillancourt. Ainsi, je ne crois pas que ces quelques commentaires rapides feront le poids aux yeux du pamphlétaire, déjà aigri par l'ignorance crasse de ses anciens professeurs. Vaillancourt n'est pas tendre envers ses lecteurs. La critique d'une société déchue dans son langage et la recherche nostalgique de la pureté perdue ne lui permettent pas de compromis envers eux. Rares seront ceux (et encore moins celles) qui se rendront au bout de ce difficile périple. Il faut dire que l'ouvrage de Vaillancourt est d'une lecture extrêmement difficile : on doit donc s'armer de patience et d'outils lexicographiques de toutes sortes pour comprendre le détail d'une argumentation hirsute où se côtoient les vers latins et des centaines de néologismes.

Le projet de cette «défense de la littérature » était audacieux, pourtant. Il devait s'inscrire en droite ligne dans le sillage de Joyce et de Céline: «Sincèrement, je préférerais ne plus écrire à écrire comme tout le monde. Il y a toujours un passionné de la grammaire chez le bon artisan du français, non un amoureux transi, mais un amant heureux, souvent un matamore escalabreux, Scarron, Céline, qui ne reculera pas devant le viol» (p. 93). La sibylle a beau être une femme, Vaillancourt ne défend pas les valeurs féminines. Au contraire, l'écriture dont il rêve en secret est explicitement masculine, non pas machiste, attention, mais simplement et vieillottement masculine, comme on pouvait vivre autrefois cette masculinité gaillarde dans les classes de latin du cours classique et par extension dans la Rome de Cicéron et de Sénèque. Les feuilles de la sibylle déplore ainsi la féminisation outrancière des valeurs morales, les «faux apitoiements, les feintes indignations» (p. 66) qui sont, au dire de l'auteur, les attributs des femmes et qui marquent la société québécoise actuelle. Les attaques contre le féminisme et les écrivaines comme Nicole Brossard et d'autres sont nombreuses et sans appel. À l'inverse des femmes, telles que les imagine Vaillancourt (toutes un peu prostituées...), l'écriture pamphlétaire, obscurcie par 
les néologismes et les particules exclamatives, doit évoquer une culture virile de l'obstacle et de la joute serrée. Quelque chose comme un bon match de hockey intérieur entre garçons dans le gymnase. Je dois dire que cette angoisse quelque peu maladive du féminin a beaucoup entravé ma lecture de cet ouvrage.

C'est sans doute le chapitre sur la langue qui est le plus révélateur à ce titre. En effet, pour Vaillancourt, la mère symbolique a été violée. L'Église québécoise d'autrefois, forte de sa pensée syncrétique avec le paganisme antique, a été envahie par les marchands de pacotille universitaires qui l'ont déparée et souillée. Le pamphlétaire rêve donc d'une littérature qui, comme chez Michelet ou Camille Roy, servirait de voie d'accès vers une spiritualité, serait ancrée dans l'institution religieuse. S'inscrivant en faux contre toutes les censures résultant du féminisme et des nouvelles critiques, Les feuilles de la sibylle renvoie à une époque pas si lointaine où le savoir se résumait à maîtriser les cycles ecclésiastiques et les rudiments du latin.

Le ton ironique de mon commentaire ne rend pas tout à fait justice, cependant, à la nouveauté, parfois fulgurante, du langage de ce livre. Certains passages surgissent avec l'intensité du désespoir et montrent l'ampleur de la quête philosophique qui sous-tend l'ouvrage: «Autrement, comment saurions-nous, seuls sur cette terre, sans grammaire, sans algèbre, sans Syntaxe latine, sans le jardin des Racines grecques, sans apparitions ordinaires d'anges une fois par lustre, réglementairement, que nous ne sommes pas morts, abandonnés sur la terre imbue de malheurs, sans espoir de récolte future, sans sépulture, sans résurrection » (p. 84). Mais de tels passages sont rares. Trop souvent, à s'en prendre à l'intelligence de son lecteur, Vaillancourt finit par perdre sa bonne volonté et son adhésion. C'est certainement ce qui m'est arrivé, malheureusement. Au lieu de prendre le pli, j'ai vite décroché et regardé ailleurs.

$$
\text { *** }
$$

Gilles Pellerin a été lui aussi frappé par la Grèce - j'allais dire, par la grâce -, non pas celle d'Homère, mais celle que lui offrait un film publicitaire, lors d'un voyage récent vers l'Europe: «la séquence immuable enfilait rapidement tout le saintfrusquin des statues antiques étêtées et manchotes. [...] Ces jolies personnes de marbre à qui il manquait le nez, ces temples auxquels l'aération ne faisait pas défaut, tout indiquait qu'on nous invitait à séjourner dans un monde de ruines ${ }^{5}$ ». L'écrivain est alors frappé par la substance discursive, linguistique même, de la «ruine» de cette culture grecque, dénaturée par le tourisme. Il lui vient alors à l'esprit le littoral du Saint-Laurent où il a grandi et où déjà, il s'en rend compte maintenant, les signes du déclin linguistique du Québec «tapissaient» le paysage. La persistance de ces signes de la ruine dans les civilisations anciennes comme dans celles du Nouveau-Monde hante le recueil d'essais de Gilles Pellerin sur la langue. Comment donc renverser la vapeur? Dans La mèche courte, plusieurs textes, livrés d'abord devant divers auditoires, perdent leur caractère fragmentaire et provisoire, mais l'urgence de dénoncer persiste. Dans 
la presse écrite et devant la récente Commission Larose sur la langue, Pellerin s'était insurgé, on s'en souvient, contre la dégradation du français au Québec. La transcription de son mémoire à ces états généraux figure d'ailleurs en première place et donne le ton polémique au recueil tout entier.

Pellerin ne tient pas à vrai dire un discours strictement politique, mais, comme Gaston Miron et Jacques Brault avant lui, il professe plutôt une morale (une dignité) de la langue nationale, valeur unificatrice du Québec moderne et, à ses yeux, garantie de civilisation. Tout se réduit à la substance linguistique de la culture. Le titre du premier chapitre, «L'intégrité par la langue», ne trompe pas. Cet essai, très lyrique, rappelle les liens «naturels» entre la langue française et les paysages laurentiens. Cette langue assume de curieuses fonctions rédemptrices: «La nature d'ici a fourni une référence indispensable à la compréhension d'une certaine longueur de radiations lumineuses; ma langue accroche aux arbres et à la lumière rasante d'octobre un mot rayonnant, elle le disculpe alors de fautes que la tradition imputait à Iscariote (prénom: Judas) et qu'on associait au soufre du bonhomme Satan. » (p. 11-12) Plus loin dans ce texte, on voit l'écrivain déambuler sur le chemin Sainte-Foy à Québec. Comme Jacques Poulin et Monique LaRue, on sent qu'il aime arpenter le territoire linguistique. Mais encore une fois, au cours de cette promenade emblématique, la présence de la langue prend une forme hyperbolique. Pellerin imagine que l'humanité entière remonte avec lui ce droit chemin de la langue maternelle dont les bordures rectilignes des arbres confirment la majesté et la justesse.

Les divers textes de La mèche courte ne sont pas tous d'une si belle teneur métaphorique. Dans «Quelques paradoxes de la langue littéraire», Gilles Pellerin se fait l'apôtre d'une littérature qui serait gardienne des valeurs sûres et, parmi celles-ci, la langue française elle-même. «L'usage magnifié de la langue, voilà ce qu'on demande à l'écrivain. » (p. 56) Par là, il faut entendre le maintien des principes de la grammaire et de la rhétorique, et une conception épurée de la littérature. Pellerin, rejetant ce qu'il appelle «la loi du bestseller», invite ses lecteurs (il s'adressait en premier lieu à des bibliothécaires) à consommer des œuvres reconnues par l'institution littéraire.

Enfin, comme chez Marc Vaillancourt, mais de façon plus limpide, la nostalgie pour le contenu des cours et la culture des collèges classiques affleure partout dans cet ouvrage, comme si la défense de la langue nationale invitait toujours le marcheur à emprunter les sentiers battus, les chemins prévisibles et rassurants du passé. À cette époque, on savait comment «séparer le bon grain de l'ivraie» (p. 80). Épouser le combat de la langue, c'est d'abord et avant tout lutter pour une mémoire vivante.

La mèche courte ne propose pas de recettes magiques à l'érosion de la langue française. En fait, certaines solutions préconisées par Pellerin paraîtront illusoires, naïves même. Mais il ressort de cette anxiété un profond besoin d'humanisme et un appel au sens critique. Par cela, au 
moins, cet ouvrage émerge quelque peu du lot, tente de tisser des réseaux. Cependant, le rêve du passé est omniprésent. Des figures anciennes s'imposent à la conscience, s'opposent au déclin ambiant, réunissent les «particules élémentaires » avant leur dispersion ultime. Eschyle, Sophocle et Euripide (dans cet ordre, toujours) veillent sur le Québec, eux qui, en leur temps d'incertitude, avaient su si brillamment résister au déclin des valeurs et à la montée fulgurante de la complexité.
1. Michel Houellebecq, Les particules élémentaires, Paris, coll. «J'ai lu », 1998.

2. Joël de Rosnay, L'homme symbiotique. Regards sur le troisième millénaire, nouvelle édition, Paris, Seuil, 2000, p. 32.

3. Chantal Deschamps, Le chaos créateur, Montréal, Guérin, 2002, 168 p.

4. Marc Vaillancourt, Les feuilles de la sibylle. Défense de la littérature, Montréal, Trait d'union, 2002, p. 60 [139 p.].

5. Gilles Pellerin. La mèche courte. Le français, la culture et la littérature, Québec, L'instant même, 2001, p. 24 [140 p.].

\section{Roman}

\section{Sortir de la littérature}

\section{Michel Biron, Université du Québec à Montréal}

Louis Gauthier, Monique Proulx, Gérard Bouchard: trois romanciers, trois genres différents. L'un écrit un petit roman tourné vers l'intériorité du narrateur, l'autre raconte une fable sur le monde actuel, le troisième reconstitue le Québec de 1900 à partir d'une famille du Lac SaintJean. Roman d'une nouvelle subjectivité, roman ultracontemporain, roman historique : ce sont là, à bien $\mathrm{y}$ penser, trois orientations majeures $d u$ roman québécois actuel, si tant est qu'une classification comme celle-ci ait quelque sens aujourd'hui.

$$
* *
$$

Voyage au Portugal avec un Allemand ${ }^{1}$ de Louis Gauthier constitue, à mon sens, l'un des romans québécois les plus émouvants et les plus justes de l'année 2002, un des rares qui continue d'exister chez le lecteur une fois tournée la dernière page. Rien de recherché ou de complaisant dans ce livre au climat sombre, grave, rien pour épater le lecteur. En ce sens, c'est ce qu'on appelle un livre de maturité, dont on sent que l'auteur n'attend ni satisfaction, ni prestige, ni consolation. L'ambition proprement littéraire est absente, laissant la place à autre chose qui aurait très bien pu n'être rien du tout. Or, justement, ce roman parvient à tromper le rien à force d'y consentir.

Il y a un monde entre les calembours en tous genres des premiers romans de Louis Gauthier (depuis Anna en 1967) et la phrase simple 